\title{
Digital Decision Support Systems for Enhanced Human Based Decision-making at the Shop Floor Management Level
}

\author{
Pernille Clausen \\ Department of Business Development and Technology, Aarhus University, Herning, Denmark
}

\begin{abstract}
This paper aims at emphasize the importance of digital decision support systems (DSS) to enhance the human based decision making at the shop floor management (SFM) level. This paper suggest that there is an increased focus on implementing digital technologies for developing DSSs that are adapted to the current threshold of the Industry 4.0 (I4.0) era. It is believed that there is a call for appliance of digital technologies for decision support, as the complexity of infrastructures at manufacturing facilities increases and the environments are becoming more uncertain. Those companies who not move rapidly and focus on being responsive will fall behind and lose market share, due to the large competition seen today. This paper suggest that the adaptation of digital DSSs at the SFM level will support the practitioners in their decision-making processes, wherefrom the performance level will increase.
\end{abstract}

\section{INTRODUCTION}

Nowadays the technologies related to the I4.0 perspective is having a strong impact on the manufacturing setup. Many manufacturing companies draws attention to the new buzzword "smart manufacturing", and as a result, I4.0 is attached to many lips [1]. Manufacturing companies operates in complex infrastructures and uncertain environments, where reliable- and up-to date information in the right proportions is crucial for conducting good decision-making, and this shouts for appliance of digital technologies to visualize reliable information [2]. The question is, how we must interpret the new relations that arises between technology- and human based decision-making, due to the fact, that decision-making at the SFM level are conducted through manual procedures [3].

This paper has the purpose to investigate how a digital DSS will affect the performance level at the SFM board meetings. Based on a retroductive approach [4], a qualitative research has been conducted, where firstly, an overview of the current use of digital DSSs at the SFM are investigated and secondly, a deeper understanding of the current use of digital DSSs are provided. To direct an answer and guide the research, the following questions are asked: "What is the current adaptation level of digital DSSs at the SFM level" and "How will the use of a digital DSS enhance human based decision-making at the SFM board meetings?" According academia and the practical findings, we lack understanding of how digital technologies are adopted to support decisionmaking at the SFM level and thereby we have no understanding of how the practitioners will interact with these. A digital DSS is in this paper understood as a physical artefact, like a dashboard, that will support in decision-making with digital technologies to enhance the response-time, improve quality of information and monitor and analyse performance data at the SFM board meeting.

Currently, smart manufacturing is on the fore, meaning, that technological systems and humans must learn to interact to achieve a stronger foundation of exploiting available data to create a strong platform for information and knowledge sharing at the SFM level [5]. Findings in literature state that smart manufacturing acknowledge the importance of big data and explore the use of data in a smarter way through digital technologies $[6,7]$. Furthermore, we must learn to expand the current design and operation of how information systems (IS) are interpreted and focus on exploit the available opportunities to create a SFM environment that reflect the demands of I4.0 to stay competitive $[8 ; 9]$.

Based on a workshop with practitioners and a theoretical review, the findings indicate, that decision-making at the SFM board meetings are accomplished by manual processes in a habitual mindset of handling the SFM board meetings in an analogue setting. This paper suggest that the use of digital DSSs will increase the performance management level at the board meetings and the SFM level slowly will adapt to the maturity level of I4.0.

The following sections is structured as follows; the next section explains the theoretical background of the study, and then the methodological considerations are set out. After this, the analysis is presented followed by a discussion and the conclusion.

\section{THEORETICAL BACKGROUND}

I4.0 has a strong influence on the manufacturing set-up [1] and has thus attracted attention from governments, industries and researchers, but still many aspect of the belonging new digitalized perspectives are unknown and uncertain [9]. Smart manufacturing unfolds from I4.0 and the term is used when discussing how the future will look like. The prevalent academia understands the future depicted as an environment where systems and humans act intelligently together and everything are connected to the internet [10] with the aim to exploit data in a smarter way and develop strong ISs [5]. In a 
smart manufacturing environment humans witness new technological gears and systems based on digital technologies [5], big data tools [11] and artificial intelligence [12]. Strong connections combine smart manufacturing and digital technologies and both highlights the importance of big data and the use of data in a smarter way $[6,7]$. In other words, these digital technologies have a huge impact on managing the performance management activities at the SFM level [13].

\section{A. Decision-making and performance management at the SFM level}

The origin of SFM is not consistently defined and either is its objectives. The expression "shop floor" origins from the Japanese word "Genba" and relate to the place where value is created [14]. In this paper SFM is defined as an integrated managerial system that facilitates the communication and controls the performance at the shop floor. "Board meetings" are conducted to facilitate the communication and control the performance at the SFM level and the meetings are often executed in open locations and facilitated by a foreman [14]. As the focal point of SFM is to achieve high manufacturing efficiency, several manufacturing activities are becoming more complex [2]. Holm [15] state that the practitioners are accomplishing the performance activities at the SFM level by standard operating procedures, manual processes as simple and monatomic task control methods without any supportive technologies to aid in decision-making [3]. It is in general seen that companies in the manufacturing industry shows a steady progress and development in terms of implementing and using digital technologies, but the transformation has not yet reached every level in the organization [7, 16]. Holm [15] among others state that the fourth industrial revolution has seemed to skip the working practice on the SFM level, by leaving the practitioners stuck in the Industry 2.0 (I2.0) era [9]. Hertle et al [14] state that there is need to show the employees at the shop floor more dedication and prepare them better for the processes at the shop floor, because there is a need to utilize unexploited information and secure that the employees are equipped to handle the pressure and thereby facilitate good performance. Holm [15] agrees upon this and do furthermore believe that the practitioners should evolve from self-controlled teams and incorporate more supportive technologies in their working practice in order to achieve a high degree of flexibility, adaptability and initiative. As data-transparency is believed to be one of the main constituent of SFM, it is important that the employees achieve transparency in order to understand the processes fully [17]. Iuga et al [17] state that there is a need to adopt methods and tools that visually ease the understanding of information and communication, so it is easier for the practitioners to assess the enormous amount of data that are available at the SFM level. Despite many companies invest huge amounts of resources in digitizing several manufacturing activities [9], many processes such as the decision-making to facilitate the performance management activities are conducted manually [18]. Yin et al [9] states that the human mindset soon must start to adjust the mindset of I4.0, otherwise we will lack the digital transformation.

Literature addressing the appliance of digital technologies at the SFM board meetings is almost non-existent $[3,19]$ and in the digital era of I4.0, the practical realities must be agile on several areas to stay competitive. Hence, there is a need to rethink todays ISs that base the foundation for decision-making to secure that information is reliable, up-to-date and assessed correctly to secure an efficient use $[2,20]$.

\section{B. The impact of the IS in decision-making at the SFM level}

The design and operation of information within a company is considered of high importance because the design of the company's overall IS and its success will affect the distribution of intra-organizational power [2]. The IS contains several information-sharing elements that facilitate planning, control, coordination and decision-making through technology and humans [21, 22]. Successful information-sharing is an important factor, because it is the information, which base the decision-making and support the relating operations. Looking at the perspective of manufacturing from the SFM level, the onus of responsiveness lies on the SFM functions, i.e. the activities that secures the performance [23]. Due to the inherent interdependence among these several activities, the associated uncertainties in each activity propagate an effect on each other, which result in complex situations at the shop floor [23]. As well as manufacturing complexity have been investigated in several decades, findings shows that the complexity has a major share to it's decision-makers [23]. MacCarty et al. [24] state that the decision hierarchy within the manufacturing environment define the level of complexity within the decision tasks, and thereby do the complexity of the decision-making decrease when moving longer down in the hierarchy. Consequently, due to a lower complexity at the lower levels in organization, the decision space at these levels are very limited [24].

The IS in a company is one of the most valuable assets in controlling activities and planning for change e.g. being agile, thereby there must be an increased focus on securing functional information-sharing and storing the information [2, 3]. The information resource is necessary for the performance of daily activities and especially in a time where the complexity and uncertainty is increasing factors in the organizational environments [9]. The use of supportive technologies for adapting to uncontrollable events seems to be necessary in order to stay responsive and competitive in such times [2, 8, 9]. Implementing new supportive technologies must be perceived as a learning process that takes time and require a solid transition strategy [25]. Adopting digital technologies to perform decision-making typically entails an intensive effort due to the huge work of identifying the right requirements for the right technology and codifying the organizational procedures and practices [25].

Many ISs seen today is often referred as stabilized systems based on the standardized responses, consisting of repeat conducted answers, where no agile allowances are included [26]. The standardized information processing is caused by the limited capacity that the human possess [27]. Decision-making based on limited information processing threatens organizational survival, because decision-making relies on a limited information basis, which not encounter all relevant change signals and thereby overlook the initiatives to act on early warnings [27]. In an agile environment, there is a need to add destabilizing elements in todays stabilized IS's, because 
companies needs to stay alert and detect problems and possible conflicts in time to stay competitive [27] and thereby it is important for the companies to have an adaptive IS that is capable to fit new conditions [26].

To summarize, there is seen a gap between the manual procedures conducted at the SFM board meetings and the digital technologies that are accompanied by I4.0. The benchmark is to evolve along with I4.0 and exploit the modern manufacturing systems that go beyond simple connections. By optimizing the manual ISs at todays SFM level by applying digital technologies, the company will secure better conditions for human based decision-making and enhanced performance at the SFM level. Academia state that being agile towards today's complex production environment require stronger exploitation of available digital technologies to stay competitive and therefore should companies start the digital transition now. Next section explains the methodological considerations.

\section{METHODOLOGY}

The paper draws on the retroductive approach [4], were a qualitative study base the data gathering for the practical findings. The data is based on a workshop with practitioners, where the purpose have been to identify and discuss the current use of digital technologies to support in decisionmaking (digital DSS) and how these will affect the SFM level. The analysis in this paper has run in an iterative loop between literature and the practical findings. The reproductive approach has been useful, since it paved the way for moving between literature and the practical findings to explore the phenomena being studied. To enhance the trustworthiness of the qualitative study the workshop was structured by the Café seminar method [28], which allows several groups to discuss the same phenomena and afterwards compare the discussion results.

The workshop was located at Aarhus University - the Department of Technology and Business Development, Herning, Denmark, and was held as a part of the research seminar "The Production of the Future" and conducted in the seminar-track "Digitalization of Lean boards". Based on a preliminary study, a survey was digitally distributed to the participants before attending the seminar. The survey was distributed to around 900 companies in the Northern Europe, 97 companies responded the survey and 38 of these companies participated the seminar-track. The purpose of the survey was to gain an overview of the current application of digital systems to aid in decision-making at the SFM level and to identify whether digital DSSs are a well-known phenomenon at the SFM level. The companies that had answered the survey was invited to elaborate and share their experiences at the seminar, and therefor was a workshop constructed to secure a structured facilitation of the answers. The workshop consisted of tree steps, see figure 1.

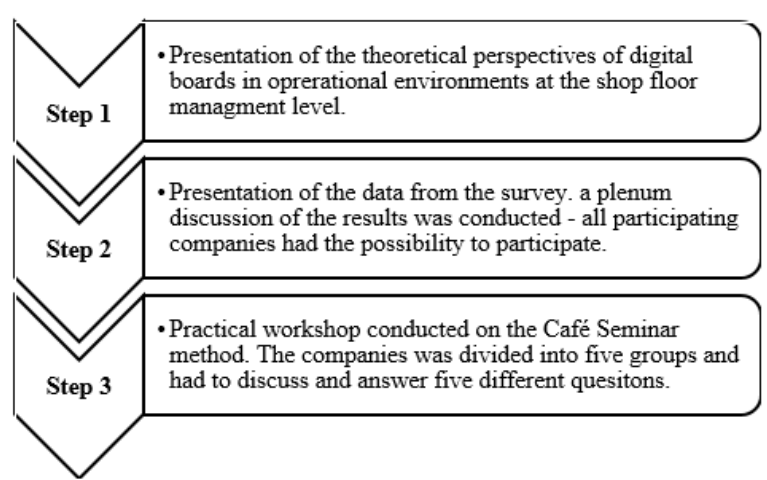

Fig. 1. Workshop structure: the workshop consisted of three steps. The third step secured the qualitative data collection.

The workshop had its purpose to facilitate a common understanding of digital technologies to support decionmaking at the SFM boards meetings and furthermore to identify the forces that influence the usage of these digital technologies. There was conducted a limitation of the field to ensure a common understanding of the area i.e. the practical workshop was conducted on a manufacturing perspective. The data collection method for the practical workshop conducted in step three, see figure 1, draws on the Café seminar method. This method base the creation of data on the exchange of experience among the practitioners (companies). The practitioners where divided in five groups and had to visit five question-stations in total. Each group was facilitated by a station-manager who had to facilitate the process, observe and take notes. Each question-station was facilitated rather different, but in general the focal point was to achieve open dialogues from several perspectives. Figure 2 shows the structure of the practical workshop.

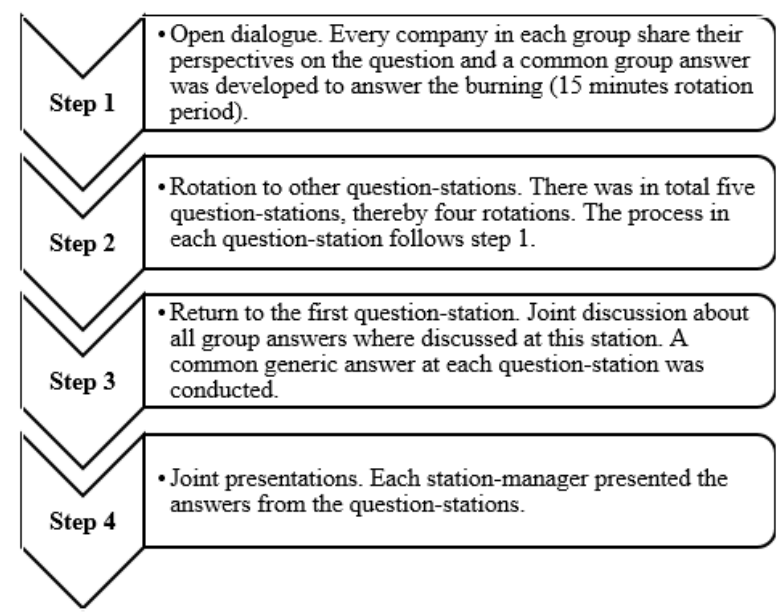

Fig. 2. Practical workshop structure, based on the Café seminar method: the workshop consisted of four steps

Through the next sections the empirical data will be presented and analyzed. The empirical findings will present the elements that hinder and enables the usage of supportive digital technologies to aid in decision-making at the SFM board meetings and afterwards will the analysis and discussion 
come up with a suggestion of how digital supportive technologies (digital DSS), will affect the SFM board meetings.

\section{PRACTICAL FINDINGS AND ANALYZING THE DATA}

After the theoretical perspectives and the data from the survey was presented, at the workshop, a plenum discussion among the practitioners and the seminar facilitators was conducted. The author of this paper participated in the discussion and had the role as a seminar facilitator, notes was taken simultaneously.

\section{A. The adaptation level of digital technologies at the SFM level}

The first area addressed in the plenum discussion was the current use of digital technologies to support decision-making at the SFM boards meetings, the findings are listed in table 1.

TABLE I. DigITAL TECHNOLOGIES TO SUPPORT DECSION-MAKING AT THE

\begin{tabular}{|l|l|}
\multicolumn{2}{|c|}{ SFM BOARD MEETINGS } \\
\hline $\begin{array}{l}\text { Digital technologies to support } \\
\text { in decision-making }\end{array}$ & Support usage in decision-making \\
\hline Microsoft PowerBI (software) & $\begin{array}{l}\text { Enhancement of visualization features } \\
\text { (KPIs) }\end{array}$ \\
\hline iObeya (software) & $\begin{array}{l}\text { Enhancement of visualization features } \\
\text { (KPIs) }\end{array}$ \\
\hline Trello (software) & $\begin{array}{l}\text { Coordination of tasks and } \\
\text { responsibilities }\end{array}$ \\
\hline $\begin{array}{l}\text { Microsoft Standard work } \\
\text { packages (software) }\end{array}$ & $\begin{array}{l}\text { Presentation of data in Excel sheets or } \\
\text { Power Point presentations (General } \\
\text { information, tact-times, KPIs) }\end{array}$ \\
\hline
\end{tabular}

The findings from table 1 , are based upon practical statements from five of the 38 participating companies, as they was the only companies that applied digital technologies to support decision-making. The findings state that the use of supportive technologies to aid in decision-making at the SFM board meetings is limited and its usage mostly accounts for visualization features.

When the companies elaborated their usage of the acquired technologies, it was discovered that almost none of the companies acquired the software to aid in decision-making in order to enhance response-time, to improve quality of information or to monitor and analyze performance data. Only one of the participating companies expressed practical experience regarding the usage of acquiring the software PowerBI to aid in decision-making. As the usage of the software in the company is on a trial period, the results regarding its supportive functionalities was unclear. Due to a very low adaptation level, it can be stated that digital DSSs not is at its fore yet at the SFM level.

\section{B. Influencing forces for the use of a digital DSS at the SFM level}

Even though the experience with digital DSSs at the companies is very limited, the companies expressed strong opinions about the opportunities the use of digital technologies may provide, when the companies participated in the practical workshop. In the practical workshop, the companies had to discuss and identify the influencing forces regarding applying digital technologies for decision support at the SFM board meetings. Based on a Force field Analysis [29] the findings are categorized into hindering- and helping forces of using digital technologies for decision support at the SFM board meetings. Table 2 summarize these findings.

TABLE II. THE PRACTICAL FINDINGS REGARDING THE INFLUENCING FORCES FOR THE ENHANCEMENT OF DECISION-SUPPORT THROUGH THE USE OF DIGITAL TECHNOLOGIES AT THE SFM BOARD MEETINGS.

\begin{tabular}{|c|c|}
\hline \multicolumn{2}{|c|}{$\begin{array}{l}\text { Influencing forces for the enhancement of decision-support through } \\
\text { digital technologies at the SFM boards meetings }\end{array}$} \\
\hline Helping forces & Hindering forces \\
\hline 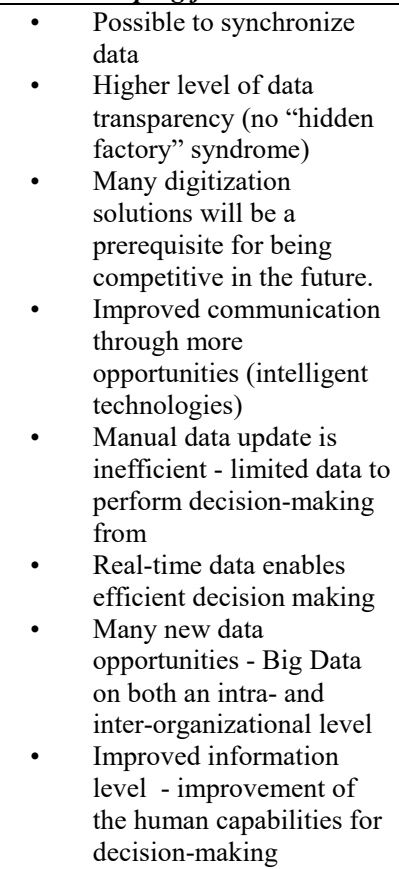 & 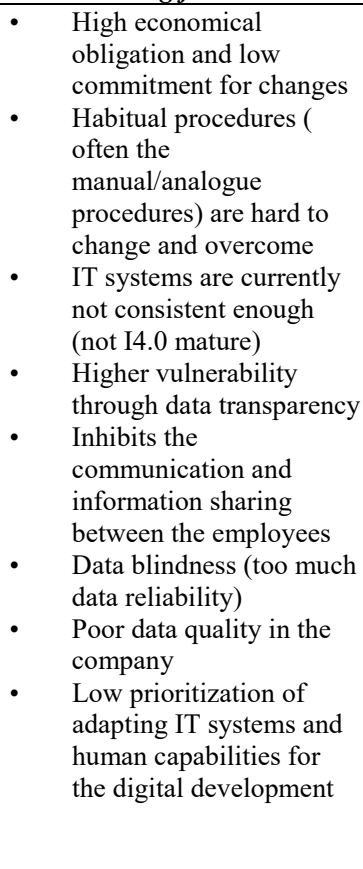 \\
\hline
\end{tabular}

The findings in table 2 show that the helping forces for the enhancement of decision-support through digital technologies are the multiple opportunities related to managing and optimize various business processes across the company. The findings state that data transparency and real-time data improve the information level and will improve the human capabilities and enable efficient decision-making to improve a competitive situation in the future. The hindering forces regarding the enhancement of decision-support through digital technologies are determined by immature IT-systems and the cultural challenges related to managing the digital transition process i.e., changing the habitual procedures of doing SFM board meetings will be resource demanding due to low human competency levels.

\section{DISCUSSION}

The prevalent academia understanding state that the current industrial maturity level is stuck in an industrial mindset belonging the industrial time of Industry 2.0 (I2.0), due to the fact, the practical execution not yet have followed the technological development in I4.0 $[9,15]$. The practical findings in this paper agrees upon that the SFM level not have 
matured along with technology at the board meetings, because the companies still are conducting the SFM activities through manual procedures.

\section{A. Enhanced decision-making though a digital DSS at the SFM level}

Kumari and Kulkarni [23] state, that the complexity level of board meetings is low, and the decision-making related to the daily operations is often non-complex. As the shop floor level mainly consist of blue-collar workers, the employees are not always educational skilled within the employment and thereby are the human capabilities required for decisionmaking often ranged low [24], [29]. Hedeberg and Jönsson [27] state that decision-making at shop floor only is based on limited information processing and this threatens organizational survival. Academia state that humans have a limited information processing capacity that in most cases conduct standardized responses with no agile adjustments, and this provide decision-making based on a limited information basis $[26,27]$. However, this paper suggest that the current complexity level of performing decision-making at the SFM level will change, if a digital DSS is adopted to support decision-making at the SFM level.

Based on the practical findings, this section suggest how it is believed the manual way of performing decision-making at the SFM board meetings will adjust, if it is supported by a digital DSS. The interoperability perspective [30] is applied to describe the ability of digital DSSs and humans to exchange, standardize and make use of information to conduct decisionmaking at the SFM board meetings. The interoperability between human and the digital DSS is defined as technical and human interoperability, where technical interoperability is a precondition for human interoperability [31], [32]. Adopting $\mathrm{Hu}$ et al's [30] definition of the syntactic and the semantic dimension of interoperability, this paper believe that a digital DSS exhibiting syntactic interoperability will replace the current low complex decision-making performed by the humans [24], due to the use of real-time data and digital technologies. The practical findings implicate that an improved information level at the SFM level will improve the human capabilities and enable efficient decision-making because the appliance of more data provide transparency and offer an expanded version of the IS to conduct decisionmaking from.

Both academia and the practical findings from table 2 state that several extended possibilities for decision-making is possible if digital technologies are applied to conduct the SFM performance activities $[8,25]$. These new possibilities will force a higher performance level, as the appliance of digital technologies to assess data release a higher complexity level within the decision-making.

By adopting, a digital DSS the interoperability will be defined as technical and human interoperability because the digital DSS and human will perform decision-making through a joint information-exchange-process that allows the human and the DSS to interpret the information equally and from the information exchange to deliver useful results, and it is believed that the performance will be enhanced. Through the opportunities digital technologies offers, a digital DSS may consist of several combined systems of same formats that are capable of communicating with each other [32] and provide the necessary data to solve the low-complex decision-making seen at the SFM level. Figure 3 visualize how this paper suggest how the performance management within the decision-making at the SFM level might change if a digital DSS is adopted to support human decision-making at the SFM level.

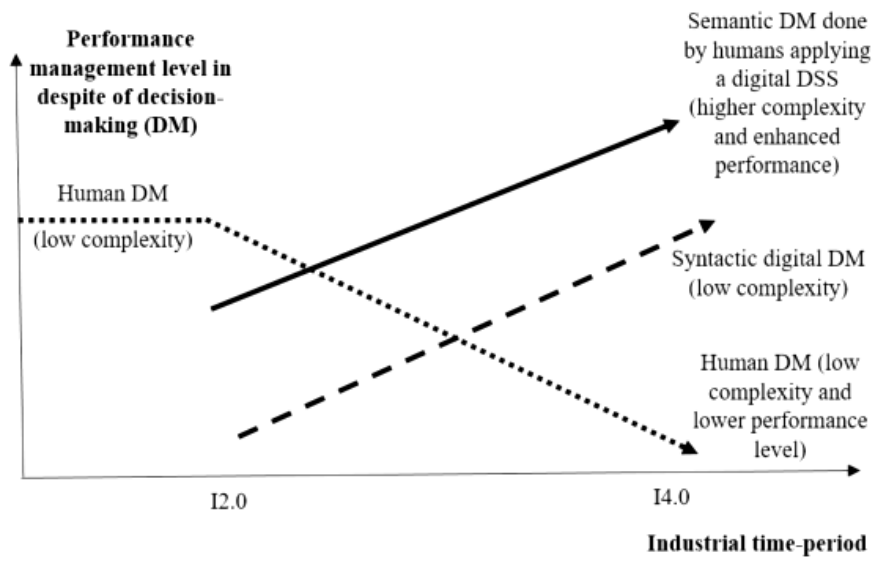

Fig. 3. Changes within the performance management level when going from Human DM to syntactic and semantic DM using a digital DSS.

Academia and the practical findings agrees upon that the technological maturity level at today's SFM level not have matured along with I4.0. However, it is suggested that the low complex decision-making currently performed by humans at the board meetings, are at the maturity level of I2.0. By adopting a digital DSS to support the decision-making, it is suggested that the decision-making at the boards meetings will receive potential to reach a technological maturity level that relate to I4.0. It is furthermore believed, that a digital DSS will support decision-making at the same performance level, as the human based decision-making performed today, wherefrom the low complex decision-makings performed by human slowly will detach. Within these changes, it is important to notify how the changes will affect the humans [14]. As the practical findings from table 2 implicates that the hindering forces are hard to overcome i.e. the competency level reflect old habitual procedures, the management at the SFM level needs to invest resources to develop the human competences. To enhance the human based decision-making, the humans must understand and learn the patterns within the digital DSS before the semantic decision-making system is durable.

\section{B. Future research perspectives}

Academia define that the concept "adaptation" as emerging and it must be considered as an important mechanism in securing the companies to stay alert and agile towards the fast changing environment. In an industrial time, where smart 
manufacturing is on its fore, reliable- and up-to-date information is vital for being successful. As both stated from academia and the practical findings, a gap between the processes of conducting SFM and processes related to the digital time that is upon us has been identified. It can be questioned why the digital transition in this area is going slow when the technology is available, and it is stated that the digital transition is a prerequisite of being competitive in the future.

As the literature is very limited on digital DSSs for decision-making at the SFM level, it is hard to state what exact impact a digital transition of the SFM level will cause. In regarding taking this research further, the findings in this paper has raised important question to ask and it would be interesting to ask the questions "how will the future SFM level practice look like" when accounting for the digital transition to happen. Another question that is important to incorporate within this perspective is how the human capabilities at the SFM level will change when the current habitual manual processes slowly are detaching.

\section{CONCLUSION}

At the outset, this paper aimed at exploring the current adaptation level of digital DSSs and how the human based decision-making at the SFM level would change if a digital DSS were adopted. The research was guided by the following research questions "What is the current adaptation level of digital DSSS at the SFM level" and "How will the use of a digital DSS enhance human based decision-making at the SFM board meetings?"

Based on the academic and practical findings, this paper claim that the use of digital technologies for decision support at SFM level not is at its fore yet and currently decisionmaking at the board meetings are conducted through manual processes. Adopting a digital DSS to support the decisionmaking at the SFM level is believed to provide clear data transparency and enhance the performance level through an extended use of data. The use of digital technologies to support decision-making will enable new opportunities and it is believed that the complexity level at the SFM level will increase and as a result, the performance level will be enhanced. Adopting digital DSSs will extend the practitioners information and knowledge level and support and improve their competences. Based on the theoretical and practical findings this paper believe that the use of digital technologies to support decision-making at SFM level will slowly close the gap, and create synergy between humans and I4.0.

\section{REFERENCES}

[1] A. Meissner, M. Müller, A. Herman og J. Metternich, »Digitalization as a catalyst for lean production: A learning factory approach for digital shop floor management, « Procedia Manufacturing, pp. 81-86, 2018.

[2] M. L. Bariff og J. R. Galbraith, »INTRAORGANIZATIONAL POWER CONSIDERATIONS FOR DESIGNING INFORMATION SYSTEMS, « Accounting, Organizations and Society, vol. 1, pp. 15-27, 1978.
[3] Å. Fast-Berglund, U. Harling og M. Åkerman, „Digitalization of meetings - from whiteboards to smart-boards, « Procedia CIRP , pp. 1125-1130, 2016.

[4] N. Blaikie, Designing Social Research, 2 red., Polity Press, 2010.

[5] C. Zhuang, J. Liu og H. Xiong, »Digital twin-based smart production management and control framework for the complex product assembly shop-floor, " The International Journal of Advanced Manufacturing Technology, pp. 1149-1163, 722018.

[6] Y. Liao, F. Deschamps, E. d. F. R. Loures og L. F. P. Ramos, »Past, present and future of Industry 4.0 - a systematic literature review and research agenda proposal, « International Journal of Production Research, pp. 3609-3629, 2017.

[7] S.-V. Buer, J. O. Strandhagen og F. Chan, »The link between Industry 4.0 and lean manufacturing: mapping current research and establishing a research agenda, «International journal of Production Research, vol. 8, pp. 1-18, 2018.

[8] Y. Chen og J. Zhu, »Measuring Information Technology's Indirect Impact, «Information Technology and Management, vol. 5, pp. 9-22, 2004.

[9] Y. Yin, K. Stecke og D. Li, »The evolutionn of production systems from Industry 2.0 through Industry 4.0, « International Journal of Production Research, pp. 848-861, 24112018.

[10] A. Syberfeldt, M. Holm, O. Danielsson, L. Wang og R. L. Brewster, »Support systems on the industrial shop-floors of the future operators'perspective on augmented reality, « 6th CIRP conference on Assembly Technologies and Systems, pp. 108-113, 2016.

[11] F. Tao og M. Zhang, »Digital Twin Shop-Floor: A New Shop-Floor, « SPECIAL SECTION ON KEY TECHNOLOGIES FOR SMART FACTORY OF INDUSTRY 4.0, vol. 5, 2017.

[12] K. Rajan og A. Safiotti, »Towards a science integrated of AI and Robotics, «Artificial Intelligence, p. 247, 2017.

[13] H. Kagerman, J. Helbig, A. Hellinger og W. Wahlster, »Securing the Future German Manufacturing Industry: Recommendations for Implementing the Strategic Initiative INDUSTRIE 4.0: Final report of the Industrie 4.0 Henderson, K. (1999)., «Visual Representations, Visual Culture and Computer Graphics in Design Engineering, 2013.

[14] C. Hertle, C. Siedelhofer, J. Metternich og A. Eberhard, »The next generation shop floor management - how to continuously develop competencies in manufacturing environments, "The 23rd International Conference on Production Research 2015, pp. 1-8, 2015.

[15] M. Holm, »The future shop-floor operators, demands, requirements andinterpretations, « Journal of Manufacturing Systems, pp. 35-42, 2018.

[16] Y. Eaidgah, A. A. Maki, K. Kurczewski og A. Abdekhodaee, »Visual management, performaance management and continuous improvement, A lean manufacturing approach, « International Journal of Six Sigma, pp. 187-210, 662015.

[17] M. V. Iuga og L. I. Rosca, »Comparison of problem solving tools in lean organizations, « 8th International Conference on Manufacturing Science and Education - MSE 2017 "Trends in New Industrial Revolution, 98 2017.

[18] M. V. Iuga, M. Schaltsysteme og L. Blaga, »Visual Communication in lean organization, « MATEC Web of Conferences, 2017.

[19] H. C, T. M, M. J og A. E, »Das Damstädter Shopfloor ManagementModell, «ZWF 112, pp. 118-121, 2017

[20] R. Sriganesh og R. Prasad, »Impact of 5G Technologies on Industry 4.0,«Wireless Pers Commun, pp. 145-159, 1332018.

[21] J. Castro, M. Kolp og J. Mylopoulos, »Towards requirements-driven information systems, «Information Systems 27, pp. 365-389, 2002.

[22] O. T. Margaret, W. T. Richard og K. B. C., »MANAGING THE THREE LEVELS OF CHANGE, «Information System Management, pp. 63-70, 1999.

[23] M. Kumari og M. S. Kulkarni, »A complexity based look-ahead mechanism for shop floor decision making, « Procedia CIRP 41, pp. 6368, 2015.

[24] B. L. MacCarty og J. R. Wilson, Human Performance Planning and Scheduling, CRC Press, 2014, pp. 388-391. 
[25] B. T. Pentland, »INFORMATION SYSTEMS AND ORGANIZATIONAL LEARNING: THE SOCIAL EPISTEMOLOGY OF ORGANIZATIONAL KNOWLEDGE SYSTEMS, " Accting., Mgmt, \& Info., pp. 1-21, 1995.

[26] S. Liaskos, S. M. Khan, M. Litoiu, M. D. Jungblut, V. Rogozhkin og J. Mylopoulos,

»Behavioraladaptationofinformationsystemsthroughgoalmodels, « Information Systems 37, pp. 767-783, 2012.

[27] B. Hedeberg og S. Jönsson, »DESIGNING SEMI-CONFUSING INFORMATION SYSTEMS FOR ORGANIZATIONS IN CHANGING ENVIRONMENTS, « Accounting, Organizations and Society, pp. 47-64, 1978.
[28] H. B. Consulting, „CAFÉ metoden - Resultater igennem bred involvering, « 2018.

[29] G. Johnson, R. Whittington, K. Scholes, D. Angwin og P. Regnér, Exploring Strategy, 10 red., Pearson, 2014, pp. 475-476.

[30] F. Hu, K. Sato, X. Z. Kun Zhou og Z. LiU, »Meaningful Experience in Service Design: Case Study of SAPAD Framework Application, « Transdisciplinary Engineering Methods for Social Innovation of Industry 4.0, pp. 526-535, 2018.

[31] J. V. Hill, »Human Interoperability, « 2010.

[32] U. Gasser og J. Palfrey, »When and How ICT Interoperability Drives Innovation, «pp. 1-33, 2007. 